\title{
Neurobiomechanical differences between successful and unsuccessful sit to stand movements performed by acute stroke patients
}

\author{
Andrew Kerr; Allan Clark; Valerie Pomeroy
}

\section{Introduction}

The sit to stand (StS) movement is a frequently performed functional task that individuals with motor impairment can find difficult, threatening their ability to live independently [1]. Understanding the characteristics that differ between a successful and an unsuccessful StS attempt could enable a more targeted approach to rehabilitation.

\section{Research question}

What are the muscle activation and kinematic differences between a successful and an unsuccessful StS movement performed by acute stroke patients?

\section{Methods}

Medically stable, acute ( $<3$ months post ictus), stroke patients, referred for rehabilitation, were invited to participate. The study had local Research Ethics Committee approval. Full body, three dimensional motion data were collected at $120 \mathrm{~Hz}$ (Oxford Metrics, UK). This was synchronised with electromyographical (EMG) signals from lower limb muscles collected at $1080 \mathrm{~Hz}$ (MT8, MIE Medical Research Ltd., UK). Participant's were instructed to stand up from a height adjusted chair, at their own speed, without the use of their arms or assistance from another person or aid. Three attempts were recorded for each participant. EMG data were collected following SENIAM guidelines and processed (filtered (bandpass (200-400), rectified and averaged) so that peak muscle activity times could be identified. Kinematic data from 15 segments were filtered (low pass, cut-off $6 \mathrm{~Hz}$ ) and reduced to the displacement of the total body CoM. Based on previous reports four variables were then selected, a priori, for comparison [2].

\section{Results}

Data were collected from 89 stroke patients. 52 participants (mean age 70.4 years) performed the movement successfully and 37 (mean age 74.6 years) did not. Using an ANOVA, statistical differences between a successful \& an unsuccessful attempt existed between all selected variables. Peak forward position of the $\mathrm{CoM}(\mathrm{f}=65.91, \mathrm{p}=0.000)$, CoM position at the time of peak quadriceps $(\mathrm{F}=43.17, \mathrm{p}=0.000)$, time difference between peak activity of ipsilateral hamstrings and quadriceps peaks $(\mathrm{F}=6.86, \mathrm{p}=0.010)$ and contralateral quadriceps $(\mathrm{F}=4.04, \mathrm{p}=0.048)$, see Table 1 .

Table 1. Key neurobiomechanical differences between successful \& unsuccessful StS movements.

\begin{tabular}{lllll}
\hline & $\begin{array}{l}\text { Peak CoM } \\
\text { forward } \\
\text { position }(\mathbf{m m})\end{array}$ & $\begin{array}{l}\text { CoM position at time } \\
\text { of quadriceps peak } \\
\text { (mm) }\end{array}$ & $\begin{array}{l}\text { Time difference between } \\
\text { contralateral quadriceps } \\
\text { peaks (s) }\end{array}$ & $\begin{array}{l}\text { Time difference between } \\
\text { ipsilateral quadriceps and } \\
\text { hamstrings peaks (s) }\end{array}$ \\
\hline $\begin{array}{l}\text { Successful } \\
\text { STS }\end{array}$ & $260.5(53.2)$ & $204.3(73.8)$ & $0.94(1.18)$ & $0.62(1.01)$ \\
\hline $\begin{array}{l}\text { Unsuccessful } \\
\text { STS }\end{array}$ & $151.7(74.6)$ & $96.5(75.9)$ & $1.47(1.27)$ & $2.15(3.95)$ \\
\hline
\end{tabular}




\section{Discussion}

This large neurobiomechanical study of acute stroke patients confirms the importance of a large forward displacement of the body $(\sim 26 \mathrm{~cm})$ for a successful $\mathrm{StS}$ movement as well as timing between this forward displacement and the synergistic activity of lower limb muscles (see Fig. 1), to lift the body vertically. While the study provides evidence to support current practice (i.e. the large forward movement of the upper body when seated) it also suggests potential benefit from training the synergies between contralateral quadriceps and ipsilateral quadriceps/hamstrings. Further work is needed to test the causal nature of these relationships in recovering independence with this important task.

\section{References:}

[1] Janssen, et al. Neurorehabil. Neural Repair, 24 (8) (2010), pp. 763-769

[2] Zablotny, et al. Arch. Phys. Med. Rehabil., 84 (11) (2003), pp. 1721-1725 